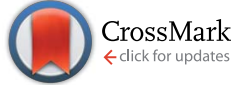

Cite this: J. Anal. At. Spectrom., 2015, 30, 1133

Received 16th December 2014 Accepted 10th February 2015

DOI: $10.1039 / \mathrm{c} 4 \mathrm{ja} 00476 \mathrm{k}$

www.rsc.org/jaas

\section{A non-chromatographic automated system for antimony speciation in natural water exploiting multisyringe flow injection analysis coupled with online hydride generation - atomic fluorescence spectrometry}

Lindomar A. Portugal, ${ }^{a}$ Laura Ferrer, ${ }^{a}$ Antonio M. Serra, ${ }^{a}$ Douglas Gonçalves da Silva, Sérgio Luis C. Ferreira ${ }^{b}$ and Víctor Cerdà ${ }^{\star a}$

A non-chromatographic automated system for the speciation and determination of inorganic and trimethylantimony (TMSb) exploiting multisyringe flow injection analysis (MSFIA) with hydride generation (HG) and atomic fluorescence spectrometry (AFS) is described. A cationic minicolumn was used for retaining the methylated forms of $\mathrm{Sb}$ which can generate hydrides, minimizing errors in the inorganic antimony speciation step. The optimization was performed in a multivariate way by employing a threevariable Box-Behnken design and a multiple response strategy. So, this method allows the quantification of $\mathrm{Sb}$ using the external calibration with aqueous standards. The method is suitable for monitoring drinking, surface and ground waters according to regulations established by the EU directives for antimony $\left(5.0 \mu \mathrm{g} \mathrm{L}^{-1}\right)$, and it was applied to the speciation of inorganic antimony and TMSb in several spiked water samples with recoveries close to $100 \%$. The detection limits were $0.03 \mu \mathrm{g} \mathrm{L}^{-1}$ for Sb(II) and $\mathrm{Sb}(\mathrm{v})$ and $0.13 \mu \mathrm{g} \mathrm{L}^{-1}$ for TMSb. The method was satisfactorily applied to the determination of $\mathrm{Sb}(\mathrm{III}), \mathrm{Sb}(\mathrm{V})$ and TMSb in different water samples collected in Balearic Islands, Spain.

\section{Introduction}

Antimony is a ubiquitous pollutant distributed in low concentrations in natural water. For this reason it is important to develop sensitive methods for its determination. Antimony is present in the aquatic environment as a result of rock weathering, soil runoff and anthropogenic activities. Because of its chemical properties, antimony is widely used in industry. Among the various industrial applications of Sb compounds, antimony trioxide $\left(\mathrm{Sb}_{2} \mathrm{O}_{3}\right)$ is profusely employed in the production of glassware and ceramics. ${ }^{1}$ Furthermore, $\mathrm{Sb}_{2} \mathrm{O}_{3}$ is added to molten glass as a clarifying agent and is used as a pigment in dyes and paints as well as in the textile industry. Several $\mathrm{Sb}$ compounds are used as additives in batteries, metal coatings and in rubber, and others are added to textiles as flame retardants. In 2010 the world mine production of Sb was estimated to be 165000 tons. $^{2}$ Also Sb is a common component of coal and petroleum. Thus $\mathrm{Sb}$ is released to the environment by industrial activities. Typical concentrations of dissolved antimony in unpolluted waters are less than $1 \mu \mathrm{g} \mathrm{L}^{-1}$. However, in

${ }^{a}$ Group of Analytical Chemistry, Automation and Environment, Department of Chemistry, University of Balearic Island, Cra. Valldemossa 7.5 km, 07122 Spain. E-mail: victor.cerda@uib.es

${ }^{b}$ Instituto de Química, Universidade Federal da Bahia, Brazil the proximity of anthropogenic sources they can reach up to 100 times the natural levels. ${ }^{3}$

Generally, the inorganic species of antimony are more toxic than the organic forms, and its compounds were considered as pollutants of priority interest by the Environmental Protection Agency of the United States (USEPA) and by the European Union (Council of the European Communities). ${ }^{3,4}$ Antimony does not show biological functions and it is easily accumulated in organisms, causing deleterious effects in humans. ${ }^{5}$ The determination of antimony content is important to protect the health of people and prevent environmental contamination due to its toxicity. ${ }^{5}$

The development of highly sensitive techniques to identify and/or to quantify $\mathrm{Sb}$ species has opened up an increasingly attractive research area for elucidating the fate of $\mathrm{Sb}$ in the different environmental compartments. A vast majority of studies have focused on methods based on high-performance liquid chromatography (HPLC), used in conjunction with an element-specific detector. These methods using HPLC separation of $\mathrm{Sb}$ species are based on anion-exchange chromatographic methods due to the predominance of $\mathrm{Sb}$ anionic species in aqueous environmental samples. ${ }^{6}$ Since the first proposal of using an anion-exchange column, ${ }^{7}$ cationic and reversed-phase chromatographic columns have also been evaluated, ${ }^{8}$ but species separation was not improved compared to 
anion-exchange methods. In this context, the accurate separation of inorganic $\mathrm{Sb}(\mathrm{III}), \mathrm{Sb}(\mathrm{v})$ and methylated $\mathrm{Sb}$ species using a single chromatographic system is notoriously problematic and less often described in the literature. Several HPLC methods have attempted such a purpose, most of them based on the use of strong anion-exchange stationary phases and complexing mobile phases to improve $\mathrm{Sb}$ (III) elution. ${ }^{6}$ Furthermore HPLC systems are complex, involving expensive instruments and dilatory methodologies.

Hydride generation (HG) techniques are widely used for the determination of volatile hydride forming elements in analytical atomic spectrometry to enhance detection power and minimize or eliminate matrix interferences while incurring relatively low additional cost and minimal sophistication. ${ }^{9}$ Usually, these techniques were combined with atomic absorption spectrometry (HG-AAS), ${ }^{\mathbf{1 0}}$ atomic fluorescence spectrometry (HG-AFS), ${ }^{11,12}$ inductively coupled plasma optical emission spectrometry (HG-ICP-OES) ${ }^{\mathbf{1 3 , 1 4}}$ and inductively coupled plasma mass spectrometry (HG-ICP-MS).$^{15,16}$ Alternative applications using the HG-AFS system can also be used. ${ }^{17}$

Not only is $\mathrm{Sb}$ (III) reduced by $\mathrm{NaBH}_{4}$, but also methylated species of $\mathrm{Sb}$ are reduced and $\mathrm{Sb}(\mathrm{v})$ is partially reduced. ${ }^{18}$ This is an important drawback in $\mathrm{Sb}$ speciation by $\mathrm{HG}$ to obtain accurate results. 8-Hydroxyquinoline was used as a masking reagent for $\mathrm{Sb}(\mathrm{v})$ and transition metals during stibine formation. ${ }^{19}$ For the determination of $\mathrm{Sb}(\mathrm{v})$ by $\mathrm{HG}$, it should be previously pre-reduced to $\mathrm{Sb}$ (III). Most methodologies for $\mathrm{Sb}$ determination have only been applied for the separation or speciation of inorganic species, $\mathrm{Sb}(\mathrm{III})$ and $\mathrm{Sb}(\mathrm{v})$, without considering the organic species of antimony. This dimethylation leads to the formation of $\mathrm{Me}_{2} \mathrm{SbH}, \mathrm{MeSbH}_{2}, \mathrm{SbH}_{3}$, and $\mathrm{Me}_{3} \mathrm{Sb}$, an issue which has been discussed extensively in the literature, but has not yet been unequivocally solved. ${ }^{15}$ Although non-chromatographic methodologies are an interesting alternative, because they are cheaper, easy to operate and faster than HPLC systems, only a single paper has addressed the use of a non-chromatographic system for antimony speciation. The author studied the influence of a combination of fluoride and iodide as a modifier for the reduction process of $\mathrm{Sb}(\mathrm{III}), \mathrm{Sb}(\mathrm{v})$ and TMSb for stibine generation using flow injection hydride generation coupled to an inductively coupled plasma atomic emission spectrometer (FI-HG-ICP-AES), and the method was applied to orange juice samples. ${ }^{20}$

Currently, multivariate optimization strategies are very popular in the development of analytical methodologies. The main advantage of their use is the low number of experiments required to achieve the optimal conditions and the indication of possible influences of some variables on others, which is not possible in univariate optimization. The response surface methodology (RSM) can be considered as one of the most important approaches for the multivariate optimization of several analytical procedures. ${ }^{21,22}$ The selection of a BoxBehnken design as a model for the multivariate optimization of analytical procedures is on account of its growth in the last few years, basically due to its higher efficiency when compared to other second-order designs like the Doehlert matrix and the
Central Composite Design and its efficiency is equal to the Doehlert matrix when three factors are studied. ${ }^{21}$

This paper proposes an automated and non-chromatographic method for the determination and speciation of $\mathrm{Sb}$ (III), $\mathrm{Sb}(\mathrm{v})$ and TMSb in complex natural water samples by HG-AFS at $n g \mathrm{~L}^{-1}$. The method has been applied to various natural water samples collected in Balearic Islands, Spain. Furthermore, the majority of the previously developed methods have been focused on the determination of high levels of antimony. The aim of this work is the determination of antimony at the $\mathrm{ng} \mathrm{\textrm {L } ^ { - 1 }}$ level in natural waters (coastal water, groundwater, and drinking water), since studies indicate that typical concentrations in unpolluted systems are less than $1 \mu \mathrm{g} \mathrm{L}^{-1} .^{3}$ In the present study a cationic exchange minicolumn was used in order to retain the methylated forms of $\mathrm{Sb}$ which can generate hydrides. In this sense, the retention of trimethylated species contributes to minimizing the errors in the determination of inorganic forms present in the sample.

\section{Experimental}

\subsection{System set-up}

The configuration of the system is presented in Fig. 1. The system consists of a multisyringe burette module with programmable speed (Multiburette 4S, Crison, Alella, Barcelona), employed as a liquid driver. It allows the simultaneous movement of four syringes, which are connected in block to the same stepper motor. Three-way solenoid valves (V1, V2, V3, and V4) (N-Research, Caldwell, NJ, USA) are placed on the head of each syringe with the aim of increasing the versatility and reducing reagent consumption. The "off" position (solenoid disabled) of the head valves connects the syringes to a right channel and the "on" position (solenoid enabled) to a left one. Moreover, the multisyringe has four additional 12 volt outputs, which can control some additional devices.

In the proposed system, four syringes were used: $\mathrm{S} 1(2.5 \mathrm{~mL})$, $\mathrm{S} 2(2.5 \mathrm{~mL}), \mathrm{S} 3(1.0 \mathrm{~mL})$ and $\mathrm{S} 4(5.0 \mathrm{~mL})$. The syringes were used as follows: S1 for propulsion of hydrochloric acid solution, S2 to dispense sodium tetrahydroborate solution, S3 to impel the mixture of potassium iodide and ascorbic acid solution to prereduce $\mathrm{Sb}(\mathrm{v})$ to ( $\mathrm{Sb}(\mathrm{III})$ and $\mathrm{S} 4$ to carry the sample. The acquisition of the peaks was achieved with only one filling of the syringe, increasing the sample frequency. The multisyringe module was equipped with two additional independent solenoid valves (V5) and (V6) (N-Research).

The solenoid valves V1, V2 and V3 control the aspiration and dispensing of the reagents, while V4 and V5 control the sample loading into the holding coil and the sample dispensing to the system. The valve V6 allows the bypass of the sample through the minicolumn. A manifold was constructed with $1.5 \mathrm{~mm}$ i.d. (used for the sample aspiration) and $0.8 \mathrm{~mm}$ i.d. (used for the rest of the system) PTFE tubes. For the sample loading, the holding coil used was $3 \mathrm{~m}$ long with a volume of $5.3 \mathrm{~mL}$.

A drying membrane (Perma Pure Inc., Toms River, NJ) utilizing nitrogen as a purge gas was connected to the outlet of the gas-liquid separator to circumvent entrainment of moisture into the AFS and subsequent quenching of the atomic 


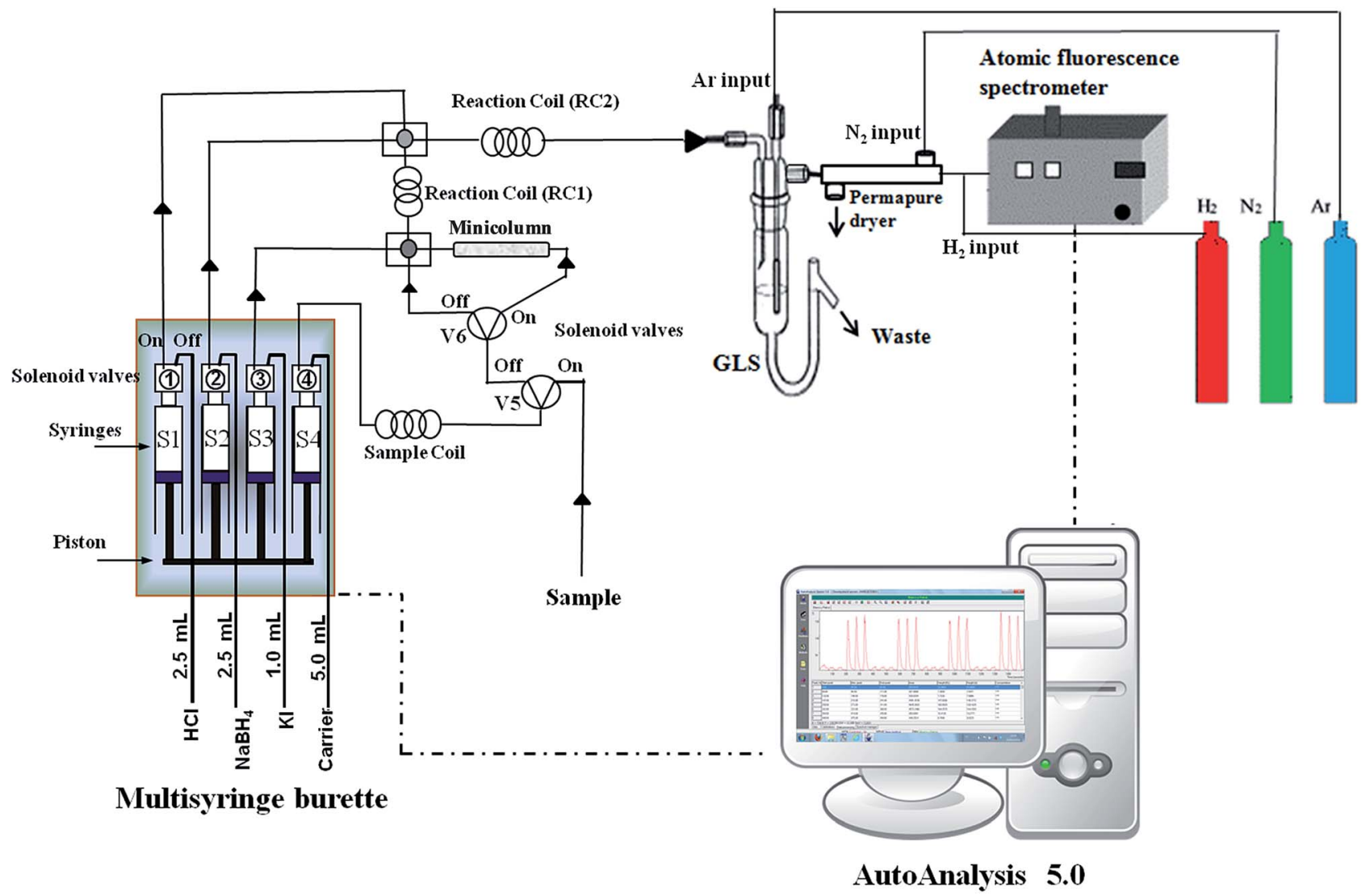

Fig. 1 Scheme of the MSFIA-HG-AFS for automated online antimony speciation.

fluorescence intensity. Water moves through the membrane wall and evaporates into the surrounding air or gas. A nondispersive atomic fluorescence spectrometer (P.S. Analytical model 10.044, Excalibur detector, PS Analytical) for on line detection equipped with an antimony boosted discharge hollow cathode lamp (primary current $17.5 \mathrm{~mA}$, secondary current 15.0 $\mathrm{mA}$, wavelength $217.6 \mathrm{~nm}$ ) was used. This spectrometer presents four internal gains and an external fine gain, which allows working on a large concentration range. The fine gain has been adjusted during the optimization, up to a fine gain of 3 , which was chosen for the lineal working range, using the internal gain at 100-fold. The transient signals were processed with the peak height. System control, data acquisition and processing of the pump, valves and syringes were performed using the software package Autoanalysis 5.0 (ref. 19) (Sciware Systems, Bunyola, Spain), version 5.0.13.5. A methacrylate minicolumn $5 \mathrm{~mm}$ in diameter and $4 \mathrm{~cm}$ in length, provided with a porous frit, was used to support the resin (DOWEX® 50 WX8, 100-200 mesh) for TMSb retention.

\subsection{Standard solutions and reagents}

All chemicals and reagents used were of analytical-grade or higher purity. Ultrapure water $\left(18.2 \mathrm{M} \Omega \mathrm{cm}^{-1}\right.$, Millipore, Watford, UK) was used throughout the study. Glassware and plasticware were cleaned by soaking in $10 \%(\mathrm{v} / \mathrm{v})$ nitric acid and rinsed with ultra-pure water prior to use.
A stock standard solution (1000 $\left.\mathrm{mg} \mathrm{L}^{-1}\right)$ of $\mathrm{Sb}(\mathrm{III})$ was prepared by dissolving antimony potassium tartrate (Carlo Erba, Italy) in $3.0 \mathrm{~mol} \mathrm{~L}^{-1} \mathrm{HCl}$ (Scharlau, Spain) solution. A stock standard solution of $\mathrm{Sb}(\mathrm{v})$ was prepared by dissolving potassium pyroantimonate acid (Carlo Erba, Italy) in $3.0 \mathrm{~mol} \mathrm{~L}^{-1}$ $\mathrm{HCl}$ (Scharlau) solution. The solutions were stable for at least 3 months at $4{ }^{\circ} \mathrm{C}$.

A stock solution $\left(1000 \mathrm{mg} \mathrm{\textrm {L } ^ { - 1 }}\right)$ of trimethylantimony(v) bromide (Sigma-Aldrich, Germany) was prepared in Milli-Q water and stored in a polyethylene bottle at $4{ }^{\circ} \mathrm{C}$ for six months.

A $6 \% \mathrm{w} / \mathrm{v}$ sodium tetrahydroborate solution (Scharlau) in sodium hydroxide $0.2 \mathrm{~mol} \mathrm{~L}^{-1}$ (Scharlau) was prepared daily.

The 8-hydroxyquinoline stock solution at $1 \%(\mathrm{w} / \mathrm{v}$, yellowish color), was prepared by dissolving $1.0 \mathrm{~g}$ of 8-hydroxyquinoline (AnalaR*, A. R.) in $10 \mathrm{~mL}$ of methanol (99.8\% Caledon), and then diluted to $100 \mathrm{~mL}$ with $\mathrm{HCl} 10 \%$ (w/v).

A stock solution of potassium iodide $50 \% \mathrm{w} / \mathrm{v}$ containing $\mathrm{L}^{-}$ ascorbic acid $10 \% \mathrm{w} / \mathrm{v}$ was prepared by dissolving $25.0 \mathrm{~g}$ of $\mathrm{KI}$ (Scharlau) and $5.0 \mathrm{~g}$ of $\mathrm{L}$-ascorbic acid (Scharlau) in $50 \mathrm{~mL}$ of ultra-pure water.

A mass of $0.2360 \pm 0.0020 \mathrm{~g}$ of the cation exchange resin DOWEX ${ }^{\circledR} 50 \mathrm{~W}-\mathrm{X} 8$ was used (polystyrene-divinylbenzene with the sulfonic functional group, 100-200 mesh).

\subsection{Sample collection and treatment}

The water samples were collected and filtered through $0.45 \mu \mathrm{m}$ cellulose acetate membrane filters immediately after sampling, 
and acidified to $\mathrm{pH} 2.0$ with hydrochloric acid and stored at $4{ }^{\circ} \mathrm{C}$. The bottles were previously washed with a $10 \% \mathrm{v} / \mathrm{v}$ nitric acid-water solution and afterward with ultrapure water. Before analyses, samples were placed with 8-hydroxyquinoline $0.05 \%$ $(\mathrm{w} / \mathrm{v})$ and $\mathrm{HCl} 10 \%(\mathrm{w} / \mathrm{v})$ and analyzed before $24 \mathrm{~h}$.

\subsection{Analytical procedure}

The analytical procedure for the determination and speciation of $\mathrm{Sb}$ can be summarized as follows in three steps:

(1) In the first step, $\mathrm{Sb}(\mathrm{III})$ is determined. The sample $(2.0 \mathrm{~mL})$ is loaded in the sample coil through S4 with V4 and V5 in the "on" position. The sample is then dispensed at $5 \mathrm{~mL} \mathrm{~min}^{-1}$ with V4 in the "on" position and V5 in the "off" position. At this time V6 switches to the "on" position allowing the sample to pass through the minicolumn and thus TMSb is retained. Then, a sample plug is mixed with $\mathrm{HCl}(1.0 \mathrm{~mL})$ and $\mathrm{NaBH}_{4}(1.0 \mathrm{~mL})$ solutions $\left(2.5 \mathrm{~mL} \mathrm{~min}^{-1}\right)$ in the reaction coil 2 (RC2). The mixture is impelled to a gas-liquid separator $\left(10 \mathrm{~mL} \mathrm{~min}{ }^{-1}\right)$, where stibine $\left(\mathrm{H}_{3} \mathrm{Sb}\right)$ is delivered to the AFS-detector by Ar gas at

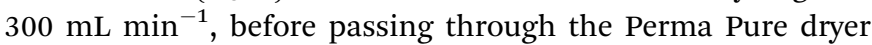
with $\mathrm{N}_{2}$ at a $300 \mathrm{~mL} \mathrm{~min}^{-1}$ flow rate. In this step, $\mathrm{Sb}(\mathrm{v})$ did not show any sign of fluorescence emission due to the use of 8hydroxyquinoline as a complexing agent and the absence of the pre-reducing agent (KI).

(2) In the second step, the total inorganic fraction is determined, i.e. $\mathrm{Sb}(\mathrm{III})$ and $\mathrm{Sb}(\mathrm{v})$. The procedure is very similar to step 1 , but $0.4 \mathrm{~mL}$ of $\mathrm{KI}$ are added $\left(1.0 \mathrm{~mL} \mathrm{~min}^{-1}\right)$ in the reaction coil 1 (RC1) in order to pre-reduce $\mathrm{Sb}(\mathrm{v})$ to $\mathrm{Sb}(\mathrm{III})$. Later, the mixture is merged in $\mathrm{RC} 2$ with $\mathrm{HCl}$ and $\mathrm{NaBH}_{4}$ solutions. The $\mathrm{Sb}(\mathrm{v})$ concentration is calculated by subtracting the $\mathrm{Sb}$ (III) concentration previously obtained. In this step, although the mechanism is still unclear, it appears that the pre-reducing solution (KI) breaks the complex formed by the association of $\mathrm{Sb}(\mathrm{v})$ and 8-hydroxyquinoline. A similar behavior was previously reported, ${ }^{19}$ using a mixture of $0.1 \%$-hydroxyquinoline $+2.0 \% \mathrm{KI}$ and achieving a recovery close to $100 \%$ for a mixture of $\mathrm{Sb}(\mathrm{III})+\mathrm{Sb}(\mathrm{v})$.

(3) In the last step, the total antimony is determined, i.e. inorganic species and TMSb. In this step, V6 is switched "off" allowing bypass to the minicolumn. Thus, the total antimony is determined and the TMSb concentration is obtained by the subtraction of previous inorganic fraction concentrations.

\section{Results and discussion}

\subsection{Optimization of the hydride generation system}

The optimization of the analytic fluorescence procedure was performed in two steps. First, a two-level full factorial design ${ }^{23}$ was implemented involving the following factors: sodium tetrahydroborate $\left(\mathrm{NaBH}_{4}\right)$ concentration (in the range from 0.1 to $0.5 \% \mathrm{w} / \mathrm{v})$ in sodium hydroxide $(\mathrm{NaOH}) 0.05 \mathrm{~mol} \mathrm{~L}^{-1}$; potassium iodide (KI) reagent concentration (from 10 to $15 \% \mathrm{w} / \mathrm{v}$ ); and hydrochloric acid concentration (from 1.0 to $5.0 \mathrm{~mol} \mathrm{~L}^{-1}$ ). The flow gas parameter ( $\mathrm{Ar}, \mathrm{N}_{2}$ and $\mathrm{H}_{2}$ were used as in the previous paper $^{\mathbf{2 4 , 2 5}}$ and preliminary studies); the sample flow rate and the acid sample were fixed according to the limitations of the column retention for TMSb. The evaluation of this factorial design demonstrated that for these experimental conditions, factors such as $\mathrm{NaBH}_{4}$, $\mathrm{KI}$ and $\mathrm{HCl}$ reagent concentration are significant for antimony hydride generation for a 95\% significance level and require a final optimization. The ANOVA table showed lack of fit and significant curvature. The curvature test was applied to the results obtained from the full factorial design to evaluate the system's behavior in the central point region. The maximum condition into the region can be identified by curvature test. Eqn (1) was used for the calculation: ${ }^{26}$

$$
\text { Curvature }=R_{\mathrm{FD}}-R_{\mathrm{CP}}
$$

where $R_{\mathrm{FD}}$ is the average of responses obtained from the experiments carried out for the factorial design, and $R_{\mathrm{CP}}$ is the average of the responses to the central point.

Analysis of the results suggested a negative curvature. This reveals the existence of an analytical region of maximum fluorescence signal near the central point of the experimental conditions.

The best analytical performance for the online speciation and detection of critical values in the antimony speciation was achieved by applying the Box-Behnken design for the chemical variables: $\mathrm{NaBH}_{4}$ concentration (\% w/v), KI concentration (\% w/v) and $\mathrm{HCl}$ concentration $\left(\mathrm{mol} \mathrm{L}^{-1}\right)$ (Table 1$)$. This design required fifteen experiments which were performed in a random manner to avoid any systematic error. The response of analytical interest was the fluorescence intensity (peak height) of the species $\mathrm{Sb}(\mathrm{v})$, $\mathrm{Sb}$ (III) and TMSb obtained in each step. To perform multiple

Table 1 Factors, levels and the experimental matrix of the BoxBehnken design

\begin{tabular}{|c|c|c|c|c|c|c|c|}
\hline \multirow{2}{*}{ Factor } & & & & \multicolumn{4}{|l|}{ Levels } \\
\hline & & & & Low $(-)$ & \multicolumn{2}{|c|}{ Mean (0) } & High $(+)$ \\
\hline \multirow{3}{*}{\multicolumn{4}{|c|}{$\begin{array}{l}\mathrm{NaBH}_{4} \text { concentration }(\% \mathrm{w} / \mathrm{v}) \\
\mathrm{KI} \text { concentration }(\% \mathrm{w} / \mathrm{v}) \\
\mathrm{HCl} \text { concentration }\left(\mathrm{mol} \mathrm{L}^{-1}\right)\end{array}$}} & 0.1 & \multicolumn{2}{|c|}{0.3} & 0.5 \\
\hline & & & & 10.0 & \multicolumn{2}{|c|}{12.5} & 15.0 \\
\hline & & & & 1.0 & \multicolumn{2}{|c|}{3.0} & 5.0 \\
\hline \multirow[b]{2}{*}{ Exp. } & \multirow[b]{2}{*}{$\mathrm{NaBH}_{4}$} & \multirow[b]{2}{*}{$\mathrm{KI}$} & \multirow[b]{2}{*}{$\mathrm{HCl}$} & \multicolumn{4}{|c|}{ Analytical signal (AU) } \\
\hline & & & & $\mathrm{Sb}(\mathrm{III})^{a}$ & $\mathrm{Sb}(\mathrm{v})^{a}$ & $\mathrm{TMSb}^{b}$ & $D$ \\
\hline 1 & - & - & 0 & 48.82 & 49.01 & 33.69 & 0.3623 \\
\hline 2 & + & - & 0 & 66.24 & 66.60 & 45.71 & 0.7099 \\
\hline 3 & - & + & 0 & 31.83 & 32.14 & 21.96 & 0.0237 \\
\hline 4 & + & + & 0 & 62.04 & 62.00 & 42.81 & 0.6237 \\
\hline 5 & - & 0 & - & 35.82 & 36.11 & 24.72 & 0.1041 \\
\hline 6 & + & 0 & - & 65.39 & 65.71 & 45.12 & 0.6927 \\
\hline 7 & - & 0 & + & 30.88 & 30.24 & 21.31 & 0.0000 \\
\hline 8 & + & 0 & + & 59.99 & 60.28 & 41.39 & 0.5851 \\
\hline 9 & 0 & - & - & 53.50 & 54.12 & 36.91 & 0.4581 \\
\hline 10 & 0 & + & - & 64.66 & 64.17 & 44.61 & 0.6728 \\
\hline 11 & 0 & - & + & 54.08 & 54.11 & 37.32 & 0.4659 \\
\hline 12 & 0 & + & + & 61.57 & 61.47 & 42.48 & 0.6139 \\
\hline 13 & 0 & 0 & 0 & 77.65 & 78.21 & 53.58 & 0.9382 \\
\hline 14 & 0 & 0 & 0 & 80.68 & 79.00 & 55.67 & 0.9836 \\
\hline 15 & 0 & 0 & 0 & 79.80 & 81.48 & 55.06 & 0.9882 \\
\hline
\end{tabular}

${ }^{a} 1.0 \mu \mathrm{g} \mathrm{L}^{-1} \cdot{ }^{b} 10 \mu \mathrm{g} \mathrm{L}^{-1}$; D: overall desirability; AU: arbitrary unit. 
response optimization for speciation and determination of the three antimony species, a mathematical-statistical tool developed by Derringer, which is based on the use of a desirability function, was used. This feature allowed us to combine in a single response (overall desirability) three distinguishing features of each species studied. The use of desirability functions for multiple response optimization experiments was proposed by Derringer and Suich. ${ }^{27}$ To obtain overall desirability, individual desirability of all responses should be determined (in this case, fluorescence intensity of $\mathrm{Sb}(\mathrm{III}), \mathrm{Sb}(\mathrm{v})$ and TMSb). Thus, each response $y_{i}(i=1,2, \ldots, m)$ is transformed into a scale-free value, which is called an individual desirability function $\left(d_{i}\right)$, where $0 \leq d_{i} \leq 1$, with 0 for an unacceptable response and 1 for a desirable response. The value of $d_{i}$ increases as the desirability of the corresponding response increases. The individual desirability function was calculated according to eqn (2), which was used to maximize the analytic responses for $\mathrm{Sb}(\mathrm{III}), \mathrm{Sb}(\mathrm{v})$ and TMSb. In this equation $y_{i}$ is the $\mathrm{Sb}$ (III), $\mathrm{Sb}(\mathrm{v})$ or TMSb fluorescence intensity; $L$ and $H$ are the lower and upper fluorescence intensities, observed in the experiments for the antimony species. The overall desirability $(D)$ was calculated by determining the geometric mean of individual desirabilities (eqn (3)).

$$
\begin{gathered}
d_{i}=\frac{\left(y_{i}-L\right)}{(H-L)} \\
D=\left(d_{1} \times d_{2} \times d_{3} \ldots d_{\mathrm{k}}\right)^{1 / k}
\end{gathered}
$$

where $k$ is the number of responses (in this case, 3). $D=1$ indicates a fully desired response, above which further improvements would have no importance.

The individual and overall desirability profiles for $\mathrm{Sb}(\mathrm{III})$, $\mathrm{Sb}(\mathrm{v})$ and TMSb are calculated according to eqn (2) and (3). Table 1 shows the overall desirability profile $(D)$. Fig. 2 shows the predicted values and desirability analyzed using the real values of the independent variables and the data processed by the STATISTICA software ${ }^{28}$ for a confidence level of $95 \%$.

The system showed critical values with maximum solution in the central point region (Table 1 and Fig. 2) and a desirability equal to 1.0, for a confidence level of 95\%. These values were: $\mathrm{NaBH}_{4} \quad 0.38 \%(\mathrm{w} / \mathrm{v}), \mathrm{HCl} 3.2 \%(\mathrm{v} / \mathrm{v})$ and $\mathrm{KI} 12.75 \%(\mathrm{w} / \mathrm{v})$. The ANOVA table shows an adjusted model for the three antimony species with low error and the correlation between observed and predicted values.

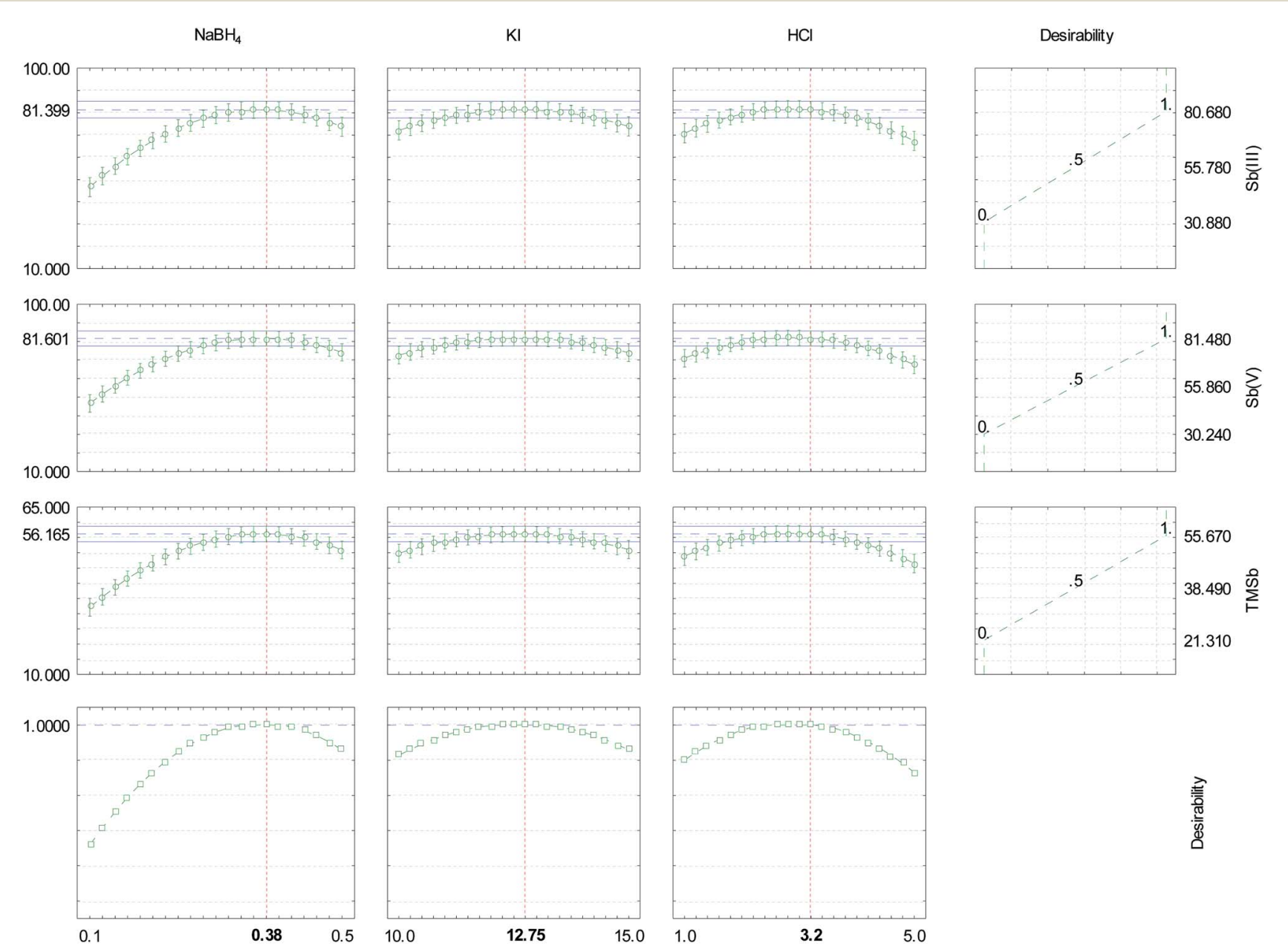

Fig. 2 Prediction and desirability profiles for simultaneous optimization of analytical signals from Sb(III), Sb(v) and TMSb species. The dashed line indicates current values after optimization using the Box-Behnken design. 


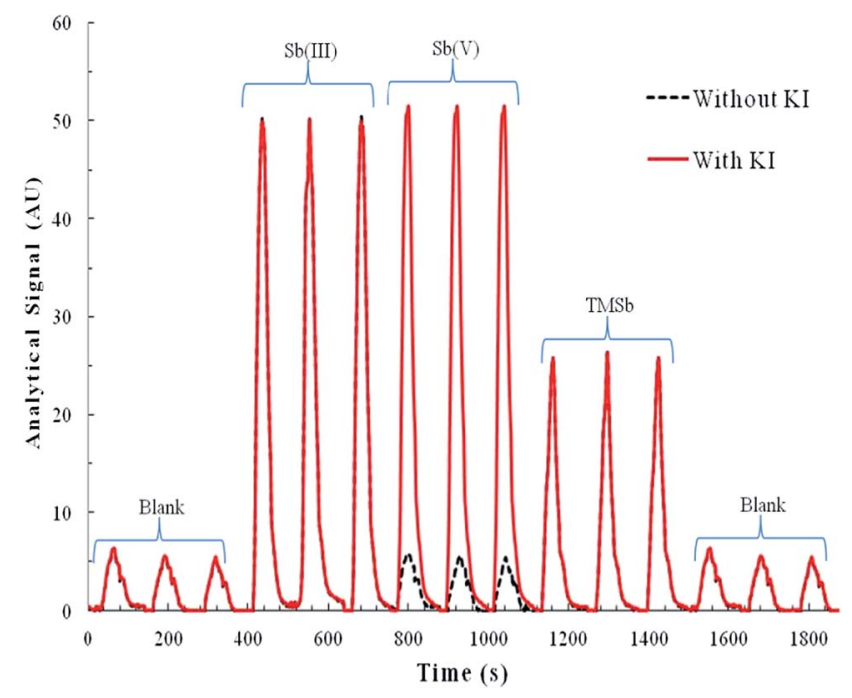

Fig. 3 Shape of the analytical signals obtained for $\mathrm{Sb}$ (III), $1.0 \mu \mathrm{g} \mathrm{L}^{-1}$, $\mathrm{Sb}(\mathrm{v}), 1.0 \mu \mathrm{g} \mathrm{L}^{-1}$ and TMSb $5.0 \mu \mathrm{g} \mathrm{L}^{-1}$, with and without $\mathrm{KI}$. All solutions were prepared in the presence of 8 -hydroxyquinoline $0.05 \%(\mathrm{w} / \mathrm{v})$. $\mathrm{AU}$ : arbitrary unit.

\subsection{Speciation methodology}

Preliminary results and those reported in the literature ${ }^{29}$ showed the difficulties encountered in developing a methodology for the determination of the three species using anionic chromatographic methods. Such difficulties may be related to the fact that soluble trimethylated antimony can mainly exist as uncharged or cationic $\left(\left[\left(\mathrm{CH}_{3}\right)_{3} \mathrm{SbOH}\right]^{+}\right)$species following the dissolution of TMSb in aqueous solution. Thus, its retention in the column cannot be explained as a single anion exchange process, whereas in aqueous solutions, $\mathrm{Sb}$ (III) exists as a neutral species at $\mathrm{pH}$ around 8 , e.g. $\mathrm{Sb}(\mathrm{OH})_{3}$, or as a complex ion dinegatively charged, e.g. $\left[\mathrm{Sb}_{2}\left(\mathrm{C}_{4} \mathrm{O}_{6} \mathrm{H}_{2}\right)_{2}\right]^{2-}$ in the presence of tartrate or EDTA, while $\mathrm{Sb}(\mathrm{v})$ exists as a mono-negatively charged species, i.e. $\left[\mathrm{Sb}(\mathrm{OH})_{6}\right]^{-}{ }^{\mathbf{1 , 6 , 3 0}} \mathrm{So}$, in this work we decided to determine antimony species $(\mathrm{Sb}(\mathrm{III}), \mathrm{Sb}(\mathrm{v})$ and $\mathrm{TMSb})$ in water

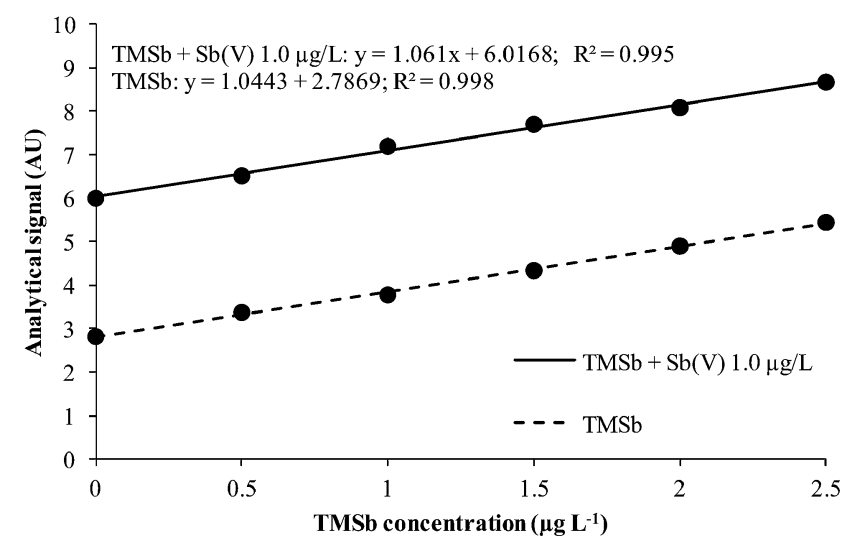

Fig. 4 Calibration curves for TMSb in aqueous medium $(\mathrm{pH}=2)$ in the absence and presence of $1.0 \mu \mathrm{g} \mathrm{L}^{-1} \mathrm{Sb}(\mathrm{v})$. Both solutions were prepared in 8-hydroxyquinoline and $\mathrm{KI}$.
Table 2 Analytical parameters of merit of the proposed method

\begin{tabular}{lll}
\hline Parameter & $\mathrm{Sb}(\mathrm{III})$ and $\mathrm{Sb}(\mathrm{v})$ & $\mathrm{TMSb}^{b}$ \\
\hline $\mathrm{LOD}\left(\mu \mathrm{g} \mathrm{L}{ }^{-1}\right)$ & 0.03 & 0.13 \\
$\mathrm{LOQ}\left(\mu \mathrm{g} \mathrm{L}{ }^{-1}\right)$ & 0.09 & 0.4 \\
Linear range $\left(\mu \mathrm{g} \mathrm{L}^{-1}\right)$ & $0.09-5.0$ & $0.4-5.0$ \\
$\mathrm{RSD} \%(n=10)^{a, b}$ & 2.8 & 3.8 \\
Injection throughput (inj. $\left.{ }^{-1}\right)$ & 30 & 30 \\
${ }^{a} \mathrm{Sb}(\mathrm{III})$ and $\mathrm{Sb}(\mathrm{v}) 1.0 \mu \mathrm{g} \mathrm{L}^{-1} .{ }^{b} \mathrm{TMSb}^{5.0 \mu \mathrm{g} \mathrm{L}^{-1} .}$ & \\
\hline
\end{tabular}

samples, using a cation exchange resin for the retention of TMSb. In this way, the analytical error is avoided since the TMSb species generates hydrides. ${ }^{31}$

L-Cysteine has been recognized as a pre-reductant for some years to reduce $\mathrm{Sb}(\mathrm{v})$ to $\mathrm{Sb}(\mathrm{III})$. However, it is known that its use yields a high value of the analytical signal of the blank. Besides, when L-cysteine is used as a masking agent, it will inevitably reduce the original $\mathrm{Sb}(\mathrm{v})$ to $\mathrm{Sb}$ (III), making speciation impossible. Therefore, potassium iodide was selected as a pre-reductant for the reduction of $\mathrm{Sb}(\mathrm{v})$ to $\mathrm{Sb}(\mathrm{III})$ and total $\mathrm{Sb}$ determination. $\mathrm{Sb}(\mathrm{III})$ and $\mathrm{Sb}(\mathrm{v})$ were determined in the absence and presence of potassium iodide. Fig. 3 shows the analytical signals obtained for the three species in study in the presence and absence of KI, without the use of the minicolumn. For this reason, it was decided to use KI because of the high efficiency of speciation of the inorganic forms of $\mathrm{Sb}$. Besides, one study reports that $\mathrm{Sb}(\mathrm{v})$ cannot be completely reduced to $\mathrm{Sb}(\mathrm{III})$ without a pre-reduction step. ${ }^{32}$

The compound 8-hydroxyquinoline was used as a masking agent in order to avoid any modification in the oxidation state of $\mathrm{Sb}\left(\right.$ III) to $\mathrm{Sb}(\mathrm{v}){ }^{19}$

\subsection{Analytical performance}

Using the optimized experimental conditions, limits of detection (LODs) $(3 \delta / s)$ and quantification (LOQs) $(10 \delta / s)$ were calculated for $\mathrm{Sb}(\mathrm{III}), \mathrm{Sb}(\mathrm{v})$ and $\mathrm{TMSb}$ in water samples following

Table 3 Instrument working conditions

\begin{tabular}{|c|c|}
\hline Sample flow rate $\left(\mathrm{mL} \min ^{-1}\right)$ & 5.0 \\
\hline Sample volume $(\mathrm{mL})$ & 2.0 \\
\hline $\mathrm{NaBH}_{4}\left(\mathrm{~mL} \mathrm{~min}{ }^{-1}\right)$ & 2.5 \\
\hline $\mathrm{NaBH}_{4}(\mathrm{~mL})$ & 1.0 \\
\hline $\mathrm{KI}\left(\mathrm{mL} \min ^{-1}\right)$ & 1.0 \\
\hline $\mathrm{KI}(\mathrm{mL})$ & 0.4 \\
\hline $\mathrm{HCl}\left(\mathrm{mL} \min ^{-1}\right)$ & 2.5 \\
\hline $\mathrm{HCl}(\mathrm{mL})$ & 1.0 \\
\hline Argon flow rate $\left(\mathrm{mL} \mathrm{min}{ }^{-1}\right)$ & 300 \\
\hline Hydrogen flow rate $\left(\mathrm{mL} \min ^{-1}\right)$ & 35 \\
\hline Dryer gas $\left(\mathrm{N}_{2}\right)$ flow rate $\left(\mathrm{mL} \mathrm{min}^{-1}\right)$ & 300 \\
\hline Lamp current primary (mA) & 17.5 \\
\hline Lamp current boost (mA) & 15.0 \\
\hline Injection throughput (inj. $\mathrm{h}^{-1}$ ) & 30 \\
\hline Gain & 100 \\
\hline Fine gain & 1 \\
\hline Signal type & Peak height \\
\hline
\end{tabular}


Table 4 Comparison with the LOD (limit of detection) obtained in procedures for antimony determination

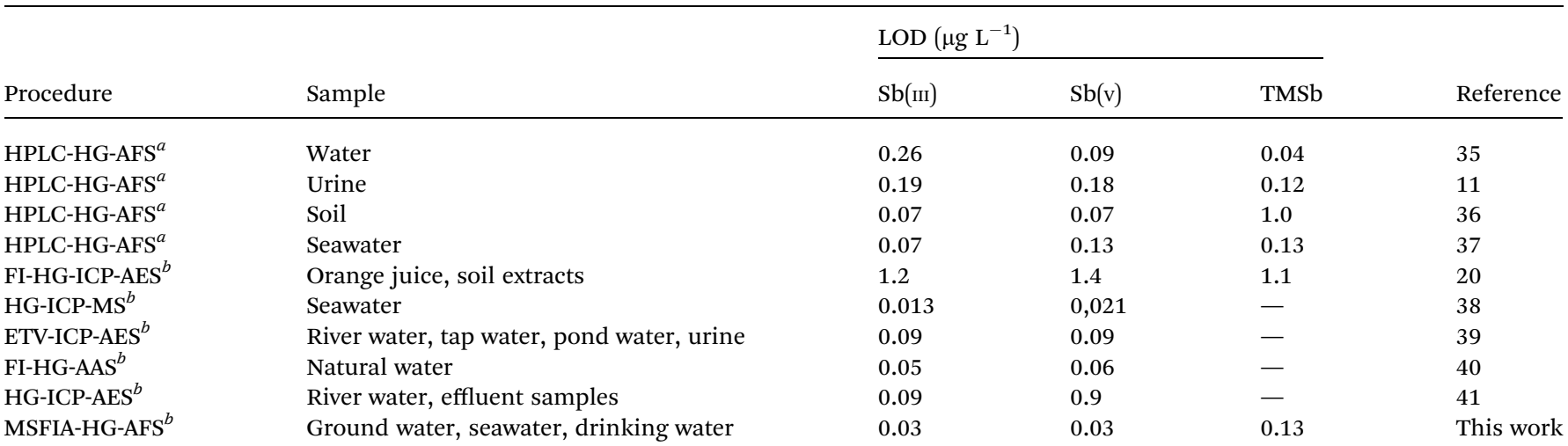

${ }^{a}$ Chromatographic technique. ${ }^{b}$ Non-chromatographic technique. HPLC: high performance liquid chromatography; HG: hydride generation; AFS: atomic fluorescence spectrometry; FI: flow injection; ICP: inductively coupled plasma; AES: atomic emission spectrometry; MS: mass spectrometry; ETV: electrothermal vapourization; AAS: atomic absorption spectrometry; MSFIA: multisyringe flow injection analysis.

the IUPAC recommendation. ${ }^{33}$ The LODs and LOQs of $\mathrm{Sb}(\mathrm{III})$ and $\mathrm{Sb}(\mathrm{v})$ are 0.03 and $0.13 \mu \mathrm{g} \mathrm{\textrm {L } ^ { - 1 }}$, respectively, while for $\mathrm{TMSb}$ they are 0.09 and $0.4 \mu \mathrm{g} \mathrm{L} \mathrm{L}^{-1}$, respectively. The sample injection throughput obtained was $30 \mathrm{~h}^{-1}$. The precision was evaluated through the relative standard deviation (RSD, \%) for the 10 replicate measurements of $\mathrm{Sb}(\mathrm{III}), \mathrm{Sb}(\mathrm{v})$ and $\mathrm{TMSb}$. Calibration was done by comparing the slope of the curve obtained with $\mathrm{Sb}(\mathrm{v})$ in aqueous standards with that obtained for analyte addition to the natural water samples. The statistical comparison allows us to determine the similitude between the slopes, with determination coefficients $R^{2}>0.99$. Therefore, it can be concluded that the proposed method can quantify $\mathrm{Sb}$ species using external calibration with aqueous standards.
In order to investigate the effect of the inorganic Sb species over the TMSb determination, two curves of TMSb were obtained: one for TMSb and other for TMSb in the presence of $1.0 \mu \mathrm{g} \mathrm{L}^{-1} \mathrm{Sb}(\mathrm{v})$ both in aqueous medium $(\mathrm{pH}=2.0)$ using 8-hydroxyquinoline as a masking agent and $\mathrm{KI}$ as a prereduction reagent for $\mathrm{Sb}(\mathrm{v})$. The slopes for both curves showed no significant difference, with the determination coefficient $R^{2}>0.99$ for a confidence level of $95 \%$, as shown in Fig. 4 . This indicates that TMSb can be determined in the presence of the inorganic form of $\mathrm{Sb}$ (assay concentrations similar to those found in fresh water), using a masking agent.

The analytical parameters used to determine the three studied species are shown in Table 2, and the instrument working conditions are summarized in Table 3.

Table 5 Antimony concentrations in water samples and spiked tests

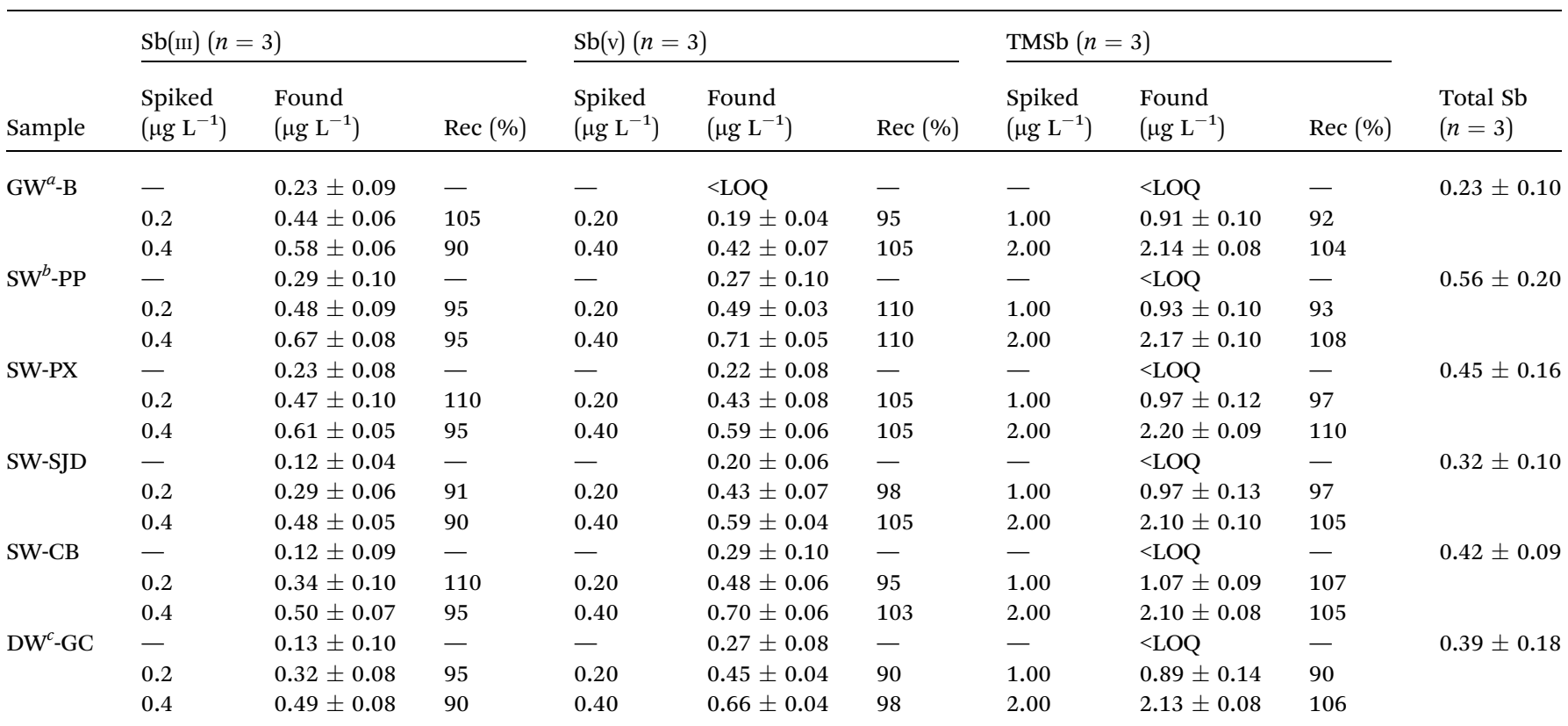

${ }^{a} \mathrm{GW}$ : groundwater. ${ }^{b} \mathrm{SW}$ : seawater. ${ }^{c} \mathrm{DW}$ : drinking water. 
The LOD, procedure used, sample matrix and chemical forms of antimony determined were compared between the proposed procedure and those of other procedures for antimony determination (Table 4).

\subsection{Validation of the proposed method and its application in water samples}

Since no certified reference materials exist for antimony speciation, the validation was performed by an addition/recovery test (IUPAC, 2002). ${ }^{34}$ Hence, in order to establish the trueness of the proposed MSFIA-HG-AFS system for antimony speciation, real samples were spiked at trace level concentrations. Recoveries of drinking waters, coastal seawaters and groundwater doped with 0.2 and $0.4 \mu \mathrm{g} \mathrm{L}^{-1}$ ranged from $90 \%$ to $110 \%$ regardless of the sample matrix complexity (see Table 5). Therefore, it was demonstrated that the automated MSFIA-HG-AFS system for antimony speciation is reliable and provides unbiased data for environmental analysis. The antimony species and total antimony were quantified by employing MSFIA-HG-AFS in water samples collected in Balearic Islands.

\section{Conclusions}

A new non-chromatographic automated method based on MSFIA coupled to HG-AFS for antimony speciation was described.

The maximum efficiency was obtained thanks to the combination of multivariate design optimization with multiresponse tools.

The proposed method provides several advantages such as a high degree of automation, an elevated precision (RSD $<5 \%$ ), and low limits of detection that allow $\mathrm{Sb}$ speciation analysis in environmental waters. Besides, a high injection frequency together with the minimization of sample and reagent volumes makes this method an efficient and environmentally friendly tool for antimony species evaluation.

The proposed method was successfully applied to several kinds of water samples, achieving recoveries of $90-110 \%$.

\section{Acknowledgements}

Lindomar Portugal thanks the Conselho Nacional de Desenvolvimento Científico e Tecnológico - CNPq (Brazil) for providing the post-doctoral studies scholarship (PDE) to carry out research work at the University of the Balearic Islands. This work was funded by the Spanish Ministry of Economy and Competitivity (CTQ2013-47461-R project) and by the Balearic Government (43/2011 cofinanced by FEDER funds).

\section{References}

1 M. Krachler, H. Emons and J. Zheng, Trends Anal. Chem., 2001, 20, 79.

2 D. E. Guberman, Antimony, in Mineral Commodity Summaries, U.S. Geological Survey, Reston, Virginia, 2014, pp. 18-19.
3 M. Filella and N. Belzile, Earth-Sci. Rev., 2002, 57, 125.

4 M. He, X. Wang, F. Wu and Z. Fu, Sci. Total Environ., 2012, $421,41$.

5 K. Bencze, Antimony, in Handbook on Metals in Clinical and Analytical Chemistry, ed. H. G. Seiler, A. Sigel and H. Sigel, Marcel Dekker, New York, 1994, pp. 227-236.

6 R. Miravet, E. Hernández-Nataren, A. Sahuquillo, R. Rubio and J. F. López-Sánchez, Trends Anal. Chem., 2010, 29, 28.

7 P. Smichowski, Y. Madrid, M. B. Calle-Gutiñas and C. Cámara, J. Anal. At. Spectrom., 1995, 10, 815.

8 J. Lintschinger, I. Koch, S. Serves, J. Feldmann and W. R. Cullen, Fresenius' J. Anal. Chem., 1997, 359, 484.

9 J. Dedina and D. L. Tsalv, Hydride Generation Atomic Absorption Spectrometry, Wiley, New York, 1995.

10 A. Erdem and A. E. Eroglu, Talanta, 2005, 68, 86.

11 W. Quiroz, H. Arias, M. Bravo, M. Pinto, M. G. Lobos and M. Cortés, Microchem. J., 2011, 97, 78.

12 A. Bellido-Martín, J. L. Gómez-Ariza, P. Smichowsky and D. Sánchez-Rodas, Anal. Chim. Acta, 2009, 649, 191.

13 A. Ilander and A. Vaisänën, Anal. Chim. Acta, 2011, 689, 178. 14 P. Qiu, C. Ai, L. Lin, J. Wu and F. Ye, Microchem. J., 2007, 87, 1.

15 M. Krachler and H. Emons, J. Anal. At. Spectrom., 2001, 16, 20.

16 J. Bowman, B. Fairman and T. Catterick, J. Anal. At. Spectrom., 1997, 12, 313.

17 P. Montesinos, M. L. Cervera, A. Pastor and M. Guardia, Talanta, 2003, 60, 787.

18 A. D'Ulivo, L. Lampugnani, G. Pellegrini and R. Zamboni, J. Anal. At. Spectrom., 1995, 10, 669.

19 T. L. Deng, Y. W. Chen and N. Belzile, Anal. Chim. Acta, 2001, 432, 239.

20 N. Ulrich, Anal. Chim. Acta, 2000, 417, 201.

21 S. L. C. Ferreira, R. E. Bruns, G. D. Matos, M. M. David, G. C. Brandão, E. G. P. da Silva, L. A. Portugal, P. S. dos Reis, A. S. Souza and W. N. L. dos Santos, Anal. Chim. Acta, 2007, 597, 179.

22 M. A. Bezerra, R. E. Santelli, E. P. Oliveira, L. S. Vilar and L. A. Escaleira, Anal. Chim. Acta, 2007, 597, 179.

23 R. E. Bruns, I. S. Scarminio and B. de Barros Neto, Statistical Design-Chemometrics, Elsevier, Amsterdam, 2006.

24 A. M. Serra, J. M. Estela and V. Cerdà, J. Anal. At. Spectrom., 2012, 27, 1858.

25 N. V. Semenova, L. O. Leal, R. Forteza and V. Cerdà, Anal. Chim. Acta, 2005, 530, 113.

26 D. G. da Silva, L. A. Portugal, A. M. Serra, S. L. C. Ferreira and V. Cerdà, Food Chem., 2013, 137, 159.

27 G. Derringer and R. Suich, J. Qual. Technol., 1980, 12, 214.

28 StatSoft Inc, Statistica 8.0, StatSoft Inc, Tulsa, USA, 2007.

29 M. J. Nash, J. E. Maskall and S. J. Hill, Analyst, 2006, 131, 724.

30 A. R. Kumar and P. Riyazuddin, Int. J. Environ. Anal. Chem., 2007, 87, 469.

31 M. Dodd, S. L. Grundy, K. J. Reimer and W. R. Cullen, Appl. Organomet. Chem., 1992, 6, 207.

32 B. Alegria, R. Barbera and R. Farre, Int. J. Environ. Anal. Chem., 1990, 38, 65.

33 G. L Long and J. D. Winefordner, Anal. Chem., 1983, 55, 712. 
34 IUPAC, Pure Appl. Chem., 2002, 74(5), 835-855.

35 A. Sayago, R. Beltrán, M. A. F. Recameles and J. L. GómezAriza, J. Anal. At. Spectrom., 2002, 17, 1400.

36 W. Quiroz, D. Olivares, M. Bravo, J. Feldman and A. Raab, Talanta, 2011, 84, 593.

37 I. D. Gregori, W. Quiroz, H. Pinochet, F. Pannier and M. Potin-Gautier, J. Chromatogr. A, 2005, 1091, 94.

38 A. C. Fornieles, A. G. Torres, E. V. Alonso, M. T. S. Cordero and J. M. C. Pavon, J. Anal. At. Spectrom., 2011, 26, 1619.
39 Y. J. Li, B. Hu and Z. C. Jiang, Anal. Chim. Acta, 2006, 576, 207.

40 F. Y. Zheng, S. H. Qian, X. Q. Li, L. X. Huang and L. X. Lin, Anal. Sci., 2006, 22, 1319.

41 A. A. Menegário, P. Smichowski, P. S. Tonello, G. Polla, E. P. Oliveira and R. E. Santelli, Anal. Chim. Acta, 2008, 625, 131. 